\title{
Pain Knowledge and Attitude among Health Care Providers working at selected hospitals of Addis Ababa, Ethiopia
}

\footnotetext{
Tesfaye Techane ${ }^{1}$, Inger Utne ${ }^{2}$, Negalign Getahun ${ }^{3}$, and Yosief Tsige ${ }^{3}$

${ }^{1}$ St. Paul's Hospital Millennium Medical College, Addis Ababa, Ethiopia

${ }^{2}$ Department of Nursing and Health Promotion, Faculty of Health Sciences, OsloMet - Oslo Metropolitan University, Oslo, Norway.

${ }^{3}$ Addis Ababa University, College of Health Sciences, School of Nursing and Midwifery, Addis Ababa, Ethiopia
}

\section{BACKGROUND}

Pain is one of the most frequent symptoms in cancer patients in Ethiopia, and health care providers (HCP) need particular knowledge and attitudes to pain and pain management.

\section{PURPOSE}

- To assess HCPs' (nurses and physicians) knowledge and attitude regarding cancer pain management, and

- To evaluate associations between sociodemographic characteristics and knowledge and attitudes regarding pain management.

\section{METHODS}

\section{Inclusion criteria:}

- HCP at two selected governmental hospitals

- Willing to participate in the study

\section{Participants:}

- Nurses $(\mathrm{n}=121)$ and physicians $(\mathrm{n}=79)$

- Nearly $60 \%$ were female

- Majorities were between 23-29 years old

- More than $70 \%$ had $<5$ years' experience

\section{Instruments}

- Demographic questionnaire

- Nurses' Knowledge and Attitudes Survey Regarding Pain (NKAS)

\section{Statistics}

- Descriptive statistics

- Logistic regression analysis

- P-values <0.05 were considered statistically significant

\section{RESULTS}

Only $40 \%$ of the HCP had more than half of the questions correctly answered. As few as $25 \%$ had at least $80 \%$ correct answers. Higher NKAS total score was associated with being male, higher income, higher age, having a formal pain management course and profession as a medical doctor.

\section{Knowledge and Attitude Scores $(\geq 50 \%$ correct} answers)

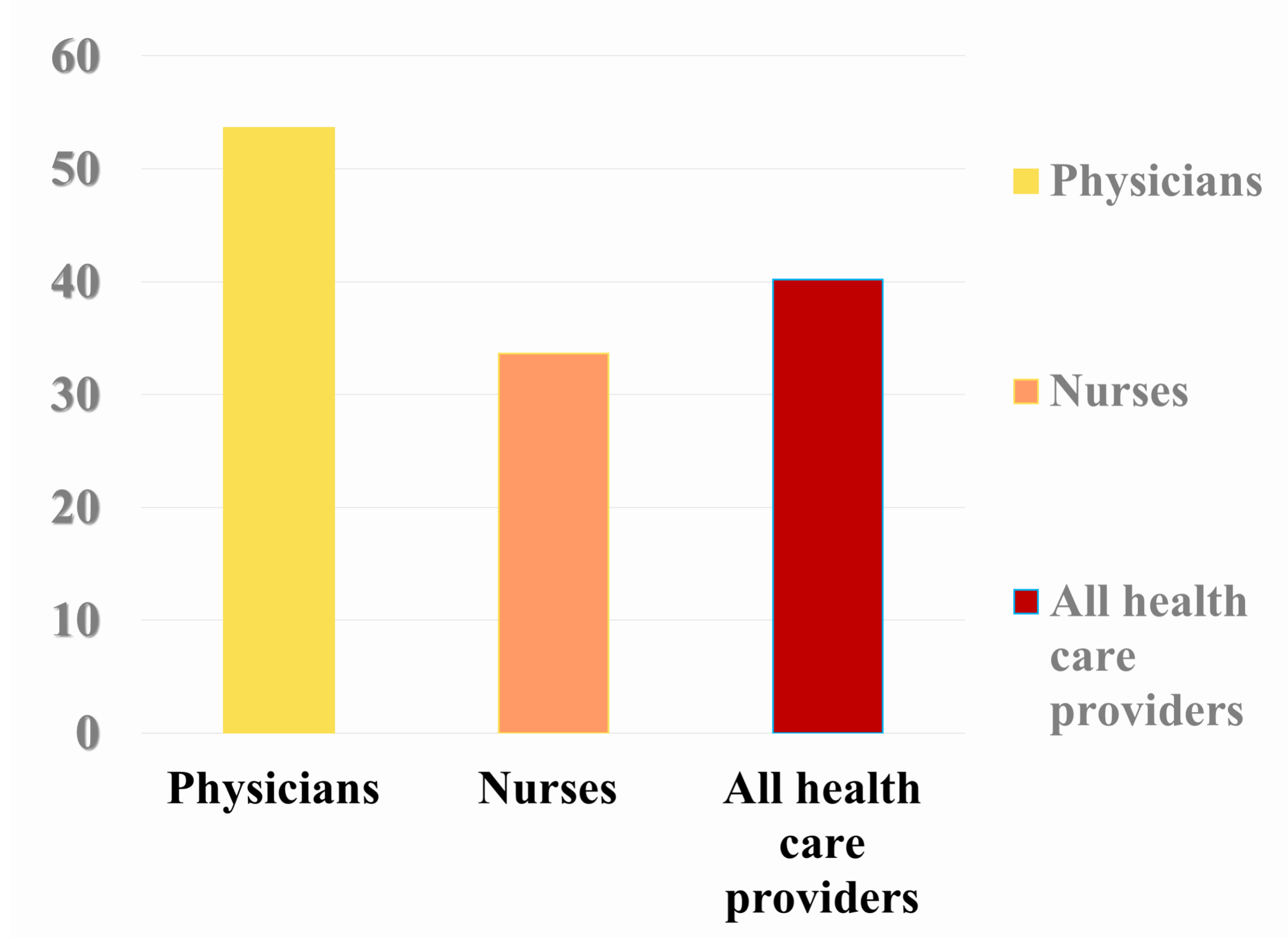

Table 1: Association between sociodemographic characteristics and knowledge and attitudes regarding pain management $(\mathrm{n}=\mathbf{2 0 0})$

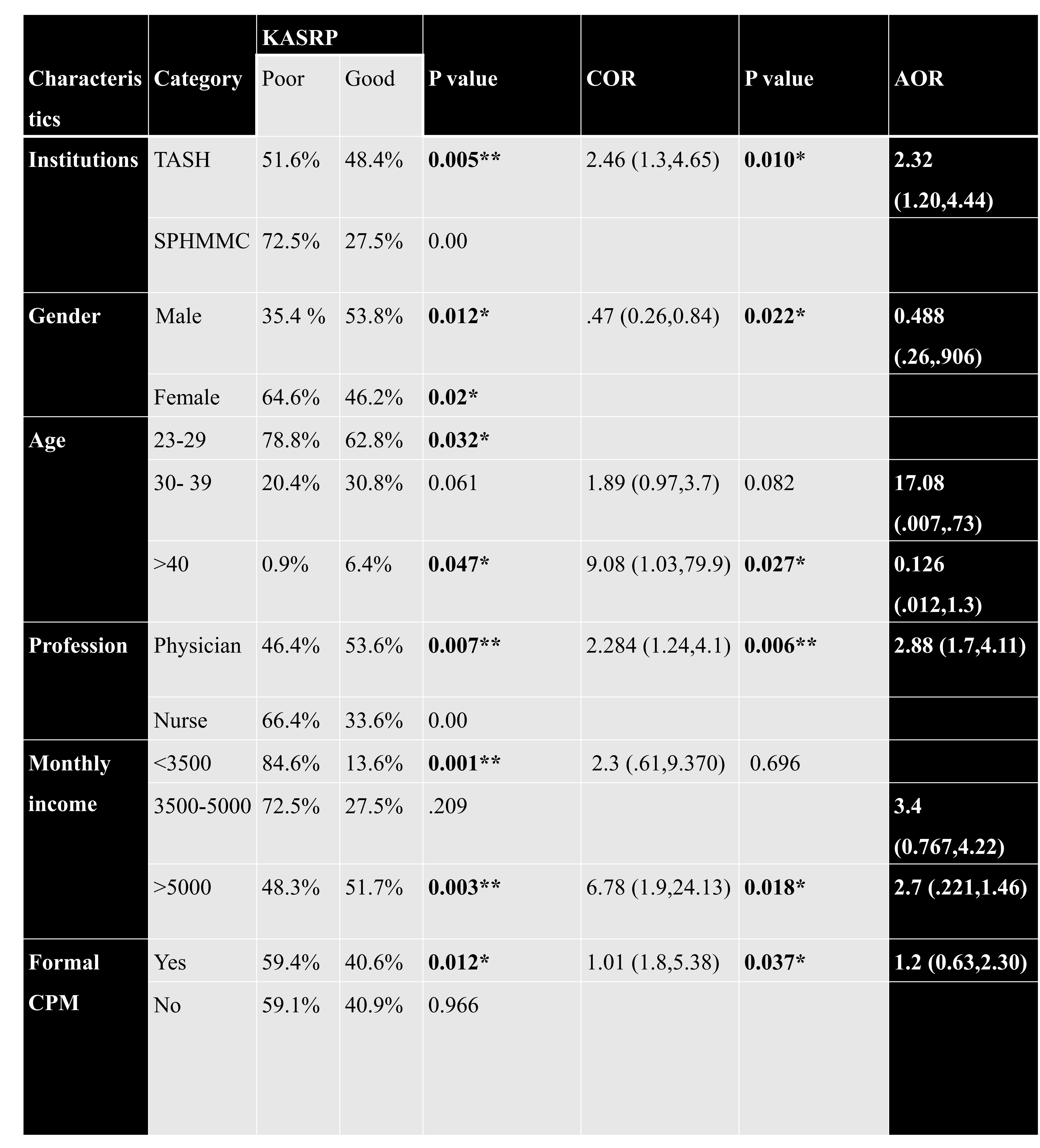

$\mathbf{P}<0.05 *, \mathbf{p}<0.01 * *$

$\mathrm{COR}=$ Crude odds ratio $\mathrm{AOR}=$ Adjusted odds ratio, $\mathrm{CPM}=$ Cancer pain management education Poor: $<\mathbf{5 0 \%}$ correct answers Good: $\geq \mathbf{5 0 \%}$ correct answers

\section{CONCLUSION}

The low NKAS total score among HCP indicated that there is a potential for improvement of knowledge and attitudes to pain. HCP should be encouraged to attend a pain management course supported by the health authorities in Ethiopia. 